\title{
Analysis of Absorption Spectra of Zinc Porphyrin, Zinc meso-Tetraphenylporphyrin, and Halogenated Derivatives
}

\author{
Kiet A. Nguyen,* Paul N. Day, and Ruth Pachter* \\ Air Force Research Laboratory, Materials and Manufacturing Directorate, AFRL/MLPJ, \\ Wright-Patterson Air Force Base, Ohio 45433-7702
}

\author{
Sergei Tretiak* \\ Los Alamos National Laboratory, MS B268, Los Alamos, New Mexico 87545 \\ V. Chernyak and Shaul Mukamel* \\ Department of Chemistry, University of Rochester, P. O. RC Box 270216, Rochester, New York 14627-0216 \\ Received: January 10, 2002; In Final Form: August 13, 2002
}

\begin{abstract}
The absorption spectra of zinc porphyrin, zinc meso-tetraphenylporphyrin, and their $\beta$-halogenated derivatives are calculated and analyzed using time-dependent density functional theory (TDDFT) and time-dependent Hartree-Fock theory based on the intermediate neglect differential overlap/spectroscopic approximation (TDHF-INDO/S) to obtain the origin of the spectral shifts in color and intensity. Analysis of the spectral shifts is carried out to account for the effects of phenyl, fluoro, chloro, and bromo substituents on the spectra. The spectroscopic trends predicted by TDHF-INDO/S compare well with the more accurate time-dependent density functional theory results and with available experimental data.
\end{abstract}

\section{Introduction}

Halogen substitution in metalloporphyrin has been shown to enhance catalytic activity ${ }^{1}$ and nonlinear optical properties. ${ }^{2}$ Zinc octahalogenated meso-tetraphenylporphyrins (ZnT$\mathrm{PPX}_{8}$ ) have been synthesized ${ }^{3-5}$ with the pyrrole rings bearing fluoro, ${ }^{5}$ chloro, ${ }^{6}$ and bromo ${ }^{3,4}$ substituents. These halogenated porphyrins exhibit pronounced changes in conformations and photophysical and chemical properties. The substitution of eight bromine atoms at the pyrrole rings in meso-tetraphenylporphyrins, for example, produced large ground-state spectral (100 $\mathrm{nm}$ for the $\mathrm{Q}$ band) and oxidation $(550 \mathrm{mV})$ potential shifts. ${ }^{3}$ The increase in oxidation potentials provides extra stability toward oxidative degradation for halogenated porphyrins. Thus, the ability of a given porphyrin to function as a catalyst or a nonlinear absorbing material is strongly dependent upon its electronic structure, which can be greatly altered by peripheral subtituents.

Recently, we found that time-dependent density functional theory (TDDFT) provides spectral resonances that are in excellent agreement with experiment for the first and second excited states of zinc porphyrins $(\mathrm{ZnP})$, zinc meso-tetraphenylporphyrin (ZnTPP), and their halogenated derivatives $\left(\mathrm{ZnPX}_{8}\right.$ and $\left.\mathrm{ZnTTPX}_{8}, \mathrm{X}=\mathrm{F}, \mathrm{Cl}, \mathrm{Br}\right)$. $^{7,8}$ This work extends to the higher energy region of the spectra of these systems to account for the effects of phenyl, fluoro, chloro, and bromo substituents on the spectral shifts in both color and intensity induced by $\beta$-halogenation, meso-tetraphenylation, and geometry distortion. Because our interest extends to the larger bichromophores and polychromophores, it will be useful to explore more approximate and less expensive levels of computation. The time-dependent Hartree-Fock theory based on the INDO/S Hamiltonian (TDHF-INDO/S) has been shown to reproduce the electronic excitations of free base and magnesium porphyrins $(\mathrm{MgP}) .^{9,10}$
In this paper, we examine the ability of TDHF-INDO/S to predict spectroscopic trends found in $\mathrm{ZnP}, \mathrm{ZnTPP}$, and their halogenated derivatives. Indeed, a good agreement between the semiempirical and TDDFT calculations will enable us to study large molecular systems and gain insight, at least qualitatively, into their spectra. The TDHF-INDO/S calculations yield the excitation energies and oscillator strengths of the lowest five allowed transitions for $\mathrm{ZnP}, \mathrm{ZnTPP}$, and their halogenated derivatives. The TDDFT calculations, extending to the higher energy region that has not been considered previously, ${ }^{7,8}$ are carried out to compare with the TDHF-INDO/S results. In addition, analyses of the TDDFT eigenfunctions and TDHFINDO/S transition densities were carried out to connect the optical response with the underlying electronic motion. The predicted TDHF-INDO/S spectra are found to be largely consistent with the TDDFT and experimental results.

\section{Computational Methods}

The structures used for TDHF-INDO/S and TDDFT calculations are obtained from previous work. ${ }^{7,8}$ These structures were optimized using Becke's three-parameter hybrid functional ${ }^{11-13}$ (B3LYP) with a combination of all-electron double- $\zeta$ basis sets (for carbon, nitrogen, fluorine, and hydrogen atoms) and effective core potentials and basis sets of Stevens et al. ${ }^{14,15}$ for heavier elements. These basis set and effective core potentials were also used in the TDDFT ${ }^{16-18}$ calculations which have been carried out by using the Gaussian $98^{19}$ program. The effects of the basis set on the excitation energies and oscillator strengths of $\mathrm{ZnP}$, examined by adding diffuse functions and using the larger triplet $\zeta$ basis set with diffuse functions, have been found to be rather small. ${ }^{20}$ The numerical procedure for TDHFINDO/S calculations has been described in detail elsewhere. ${ }^{21-23}$ The ZINDO code was used first to generate the INDO/S 

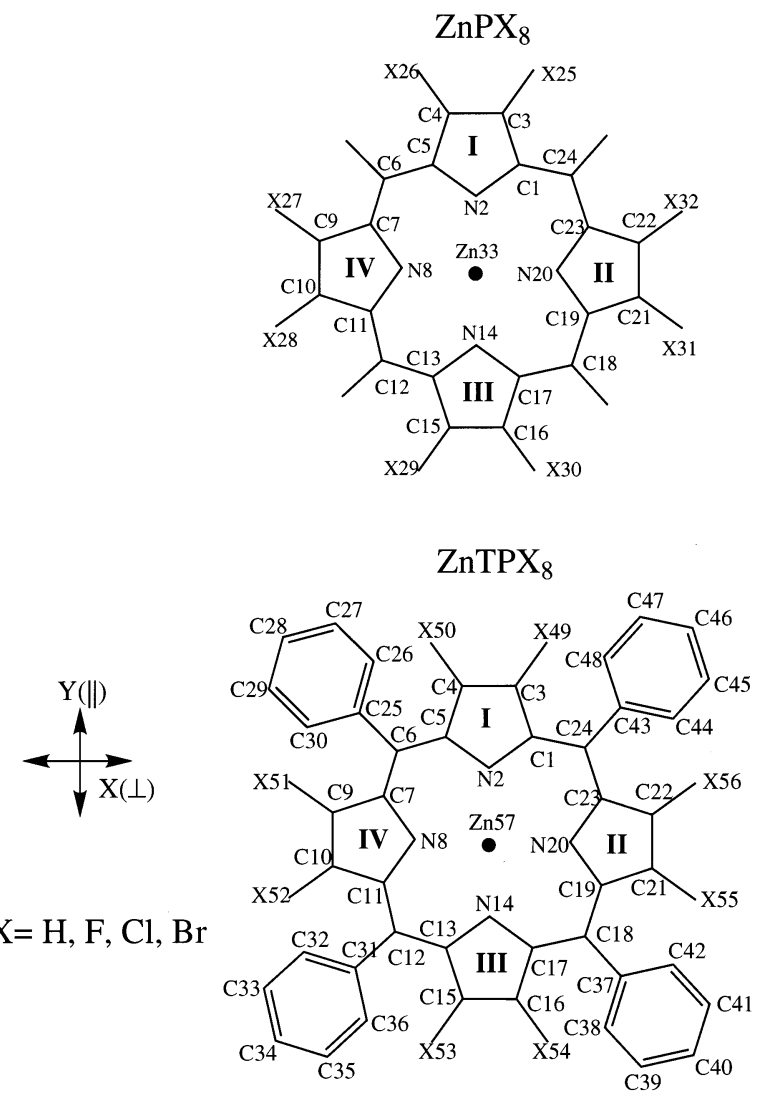

Figure 1. Labeling scheme for zinc porphyrins $(\mathrm{ZnP})$ and zinc tetraphenylporphyrins (ZnTPP).

Hamiltonian ${ }^{24-27}$ and the corresponding Hartree-Fock groundstate density matrixes, ${ }^{28,29}$ which can be used for computing the TDHF-INDO/S eigenmodes. ${ }^{21,22}$ This procedure is particularly suitable for off resonant static response computations where only transitions with nonzero oscillator strengths are calculated. In this work, the Krylov-space oblique Lanczo algorithm ${ }^{23,30}$ is used to obtain more accurate eigenvalues and eigenvectors. This method has smaller memory requirements compared to the similar Arnoldi and Davidson techniques ${ }^{23,30,31}$ for non-Hermitian eigenvalues of sparse matrixes.

We calculated the TDHF-INDO/S linear absorption of the molecules displayed in Figure 1 up to $6.5 \mathrm{eV}$. It requires computing $\sim 100$ and $\sim 200$ electronic modes for $\mathrm{ZnPX}_{8}$ and $\mathrm{ZnTPX}_{8}$ molecules, respectively. To connect the optical response with the underlying electronic motions, we examined the DFT ground- and excited-state wave functions and the complementary TDHF-INDO/S transition density matrixes or the electronic normal modes. ${ }^{32,33}$ Because the dominant features in linear absorption spectra are of the $\pi \rightarrow \pi^{*}$ type, we focus our analysis on the $\pi$-part of the transition density matrixes. The size of the $\pi$-transition density matrixes is equal to the number of heavy atoms in the molecule, labeled according to Figure 1. For $\mathrm{ZnPX}_{8}$ and $\mathrm{ZnTPPX}_{8}$ families these are $33 \times 33$ and $57 \times 57$ matrixes, respectively. The off-diagonal elements show the amplitude of having an excess hole at $n$ and an electron at $m$. Hole and electron dynamics is thus shown along the $x$ and $y$ axes, respectively. The coherences, which measure how far apart different atoms communicate, control the scaling of optical properties with molecular size. ${ }^{32,33}$ This could be realized by drawing the analogy with the particle-in-box model. The extent of electronic coherences is correlated with the red shift for excitation energy in spectra of molecules with different substituents.

\section{Results and Discussion}

We begin with some general observations about the computed and experimental spectra. The computed TDDFT and TDHFINDO/S excitation energies and oscillator strengths for $\mathrm{ZnP}$ and their corresponding $\beta$-halogenated derivatives are listed in Table 1. Table 2 lists excitation energies and oscillator strengths for ZnTPP and ZnTPPX 8 for low-energy transitions. The computed TDHF-INDO/S high-energy transitions with oscillator strengths larger than 0.001, which may have signatures in the linear absorption spectra, are given in the Supporting Information along with absorption profiles to show overall trends in the spectra. Available experimental data are also included in the tables for comparison. The TDDFT excitation energies are useful reference values for $\mathrm{ZnPX}_{8}$, where experimental data are not presently available. The experimental linear absorption spectra of these porphyrins can be divided into three distinct spectral regions. . $^{3,34-36}$ The lowest $\mathrm{Q}$ band is weak. This transition is doubly degenerate in zinc porphyrins. At intermediate frequencies the Soret (B) band is more intense, whereas the following (N) transition is weaker. The high-frequency $\mathrm{L}$ and $\mathrm{M}$ transitions are also weak. The TDDFT one-electron contributions to these allowed excitations are summarized in Figures 2 and 3. Overall, the TDDFT and TDHF-INDO/S excitation energies are in good agreement with experiment for the $\mathrm{Q}$ and $\mathrm{B}$ bands. The mean deviations of $0.19(-0.46)$ and $0.29(-0.14) \mathrm{eV}$ are obtained with TDDFT (TDHF-INDO/S) for the $\mathrm{Q}$ and $\mathrm{B}$ bands of $\mathrm{ZnP}$, $\mathrm{ZnTPP}$, and $\mathrm{ZnTPPX}_{8}(\mathrm{X}=\mathrm{F}, \mathrm{Cl}, \mathrm{Br})$, respectively. The N, L, $\mathrm{M}$, and $\mathrm{X}$ bands of $\mathrm{ZnP}, \mathrm{ZnTPP}$, and their halogenated derivatives have not been characterized theoretically. For the high-energy bands in ZnTPP, the TDHF-INDO/S excitation energies are in reasonable agreement with experiment. A detailed analysis of the spectra and trends will be presented in the coming sections.

1. ZnP and $\mathbf{Z n P X}_{\mathbf{8}}$. The $\mathrm{Q}$ and $\mathrm{B}$ band metalloporphyrins were first assigned by Gouterman using the four-orbital model ${ }^{34}$ that includes two highest occupied (HOMO and HOMO-1) and unoccupied (LUMO and LUMO+1) molecular orbitals. The HOMO and HOMO-1 are nearly degenerate, and the LUMOs are degenerate. Energetically, these orbitals are well separated from the rest of the occupied and virtual orbitals (see Figures 2 and 3). The unique MO arrangement in porphyrins provides a basis for the interpretation of their Q and B bands by the fourorbital model. For $\mathrm{ZnP}$, the weak $\mathrm{Q}$ band is assigned to $1{ }^{1} \mathrm{E}_{\mathrm{u}}$, which is described by a plus combination of the one-electron excitations from the HOMO and HOMO-1 to the degenerate LUMOs, $1 \mathrm{a}_{1 \mathrm{u}} \rightarrow 5 \mathrm{e}_{\mathrm{g}}$ and $3 \mathrm{a}_{2 \mathrm{u}} \rightarrow 5 \mathrm{e}_{\mathrm{g}}$. The $\mathrm{B}$ band is described by the minus combination of the $1 \mathrm{a}_{1 \mathrm{u}} \rightarrow 5 \mathrm{e}_{\mathrm{g}}$ and $3 \mathrm{a}_{2 \mathrm{u}} \rightarrow 5 \mathrm{e}_{\mathrm{g}}$ configurations. The interpretation provided by the four-orbital model is qualitatively consistent with the TDDFT, ${ }^{20} \mathrm{CASSCF} /$ MRPT, ${ }^{37}$ and CI calculations. ${ }^{38,39}$

Energetically, the computed TDHF-INDO/S and TDDFT transition energies of the $\mathrm{Q}$ band $\left(1^{1} \mathrm{E}_{\mathrm{u}}\right)$ deviate by -0.43 and $+0.26 \mathrm{eV}$ from the spectral maximum in methanol, respectively. The corresponding deviations for the $\mathrm{B}$ band $\left(2^{1} \mathrm{E}_{\mathrm{u}}\right)$ are -0.09 and $+0.41 \mathrm{eV}$. TDDFT thus works better for the $\mathrm{Q}$ band whereas TDHF-INDO/S is better for the B transition. We note that significant solvation effects are observed for $\mathrm{ZnP}:{ }^{40-42}$ spectral shifts of 0.18 and $0.23 \mathrm{eV}$ are observed for the $\mathrm{Q}$ and $\mathrm{B}$ bands, respectively, upon going from a micellar solution of cetyltrimethylammonium chloride ${ }^{41}$ to $n$-octane for $\mathrm{ZnP} .{ }^{40}$ Solvation effects probably cause the larger than expected errors obtained by TDDFT because the gas-phase experimental excitation energies for ZnTPP are in excellent agreement with the TDDFT energies (see Tables 1 and 2). Solvation effects, 
TABLE 1: Excitation Energies (eV) and Oscillator Strengths $(f)$ for Zinc Porphyrins

\begin{tabular}{|c|c|c|c|c|c|c|c|}
\hline \multirow[b]{2}{*}{ system/transition } & \multicolumn{2}{|c|}{ energy } & \multicolumn{2}{|c|}{ energy shift } & \multicolumn{2}{|c|}{$f$} & \multirow[b]{2}{*}{ assignment } \\
\hline & $\mathrm{TDDFT}^{b}$ & $\mathrm{TDHF}^{c}$ & TDDFT & TDHF & TDDFT & TDHF & \\
\hline \multicolumn{8}{|l|}{$\mathrm{ZnP}^{a}$} \\
\hline $1^{1} \mathrm{E}_{\mathrm{u}}$ & 2.44 & 1.75 & 0.00 & 0.00 & 0.0020 & 0.0434 & Q \\
\hline $2^{1} \mathrm{E}_{\mathrm{u}}$ & 3.54 & 3.04 & 0.00 & 0.00 & 0.8892 & 1.3157 & $\mathrm{~B}$ \\
\hline $3^{1} \mathrm{E}_{\mathrm{u}}$ & 3.84 & 3.68 & 0.00 & 0.00 & 0.0522 & & \\
\hline $4^{1} \mathrm{E}_{\mathrm{u}}$ & 4.29 & 4.30 & 0.00 & 0.00 & 0.1750 & 0.0318 & $\mathrm{~N}$ \\
\hline $5^{1} \mathrm{E}_{\mathrm{u}}$ & 5.49 & 5.00 & 0.00 & 0.00 & 0.0764 & 0.1890 & $\mathrm{~L}$ \\
\hline $6^{1} \mathrm{E}_{\mathrm{u}}$ & 6.04 & 5.24 & 0.00 & 0.00 & 0.0050 & 0.1486 & M \\
\hline \multicolumn{8}{|l|}{$\mathrm{ZnPF}_{8}$} \\
\hline $1^{1} \mathrm{E}_{\mathrm{u}}$ & 2.47 & 1.74 & -0.03 & 0.01 & 0.0020 & 0.0211 & Q \\
\hline $2^{1} \mathrm{E}_{\mathrm{u}}$ & 3.41 & 3.74 & 0.43 & -0.06 & 0.0435 & & \\
\hline $3^{1} \mathrm{E}_{\mathrm{u}}$ & 3.65 & 3.03 & -0.11 & 0.01 & 0.7606 & 1.4014 & B \\
\hline $4^{1} \mathrm{E}_{\mathrm{u}}$ & 3.80 & 4.00 & 0.49 & 0.30 & 0.3498 & 0.0169 & $\mathrm{~N}$ \\
\hline $5^{1} \mathrm{E}_{\mathrm{u}}$ & 5.35 & 4.61 & 0.14 & 0.39 & 0.0548 & 0.1942 & $\mathrm{~L}$ \\
\hline $6^{1} \mathrm{E}_{\mathrm{u}}$ & 6.09 & 5.19 & 0.05 & 0.05 & 0.0044 & 0.1022 & M \\
\hline \multicolumn{8}{|l|}{$\mathrm{ZnPCl}_{8}$} \\
\hline $1^{1} \mathrm{E}$ & 2.36 & 1.74 & 0.08 & 0.01 & 0.0111 & 0.0363 & Q \\
\hline $2^{1} \mathrm{E}_{\mathrm{u}}$ & 3.26 & 3.69 & 0.58 & -0.01 & 0.2003 & & \\
\hline $3^{1} \mathrm{E}_{\mathrm{u}}$ & 3.44 & 3.00 & 0.10 & 0.04 & 0.7691 & 1.4409 & B \\
\hline $4^{1} \mathrm{E}_{\mathrm{u}}$ & 3.59 & 4.08 & 0.70 & 0.22 & 0.3300 & 0.0373 & $\mathrm{~N}$ \\
\hline $5^{1} \mathrm{E}_{\mathrm{u}}$ & 4.95 & 4.69 & 0.54 & 0.31 & 0.1277 & 0.2094 & $\mathrm{~L}$ \\
\hline $6^{1} \mathrm{E}_{\mathrm{u}}$ & 5.57 & 5.16 & 0.47 & 0.08 & 0.0100 & 0.1064 & M \\
\hline \multicolumn{8}{|l|}{$\mathrm{ZnPBr}_{8}$} \\
\hline $1^{1} \mathrm{E}$ & 2.34 & 1.73 & 0.10 & 0.02 & 0.0166 & 0.0459 & Q \\
\hline $2^{1} \mathrm{E}_{\mathrm{u}}$ & 3.18 & 3.68 & 0.66 & 0.00 & 0.2008 & & \\
\hline $3^{1} \mathrm{E}_{\mathrm{u}}$ & 3.37 & 2.98 & 0.17 & 0.06 & 0.7806 & 1.5104 & B \\
\hline $4^{1} \mathrm{E}_{\mathrm{u}}$ & 3.47 & 4.11 & 0.82 & 0.19 & 0.3615 & 0.0447 & $\mathrm{~N}$ \\
\hline \multirow{2}{*}{$5^{1} \mathrm{E}_{\mathrm{u}}$} & 4.82 & 4.71 & 0.67 & 0.29 & 0.1542 & 0.2168 & $\mathrm{~L}$ \\
\hline & & 5.17 & & 0.07 & & 0.1100 & M \\
\hline
\end{tabular}

${ }^{a}$ Spectral maxima in $\mathrm{CH}_{3} \mathrm{OH}$ are $2.18(\mathrm{Q}, f=0.005), 3.13(\mathrm{~B}, f=0.98), 3.29$ (shoulder), $4.07(\mathrm{~N}, f \sim 0.2), 5.18(\mathrm{~L}, f \sim 0.1)$, and $5.50(\mathrm{M}, f$ $\sim 0.1) .{ }^{39}$ Spectral maxima in $n$-octane are $2.23(\mathrm{Q}), 3.18(\mathrm{~B})$, and 3.35. ${ }^{40}$ Spectral maxima in a micellar solution of cetyltrimethylammonium chloride are $2.03(\mathrm{Q})$ and $2.95 \mathrm{eV}(\mathrm{B}){ }^{41}$ Spectral maxima in $\mathrm{C}_{6} \mathrm{H}_{6}$ are $2.21(\mathrm{Q}), 3.09(\mathrm{~B})$, and $\sim 3.3$ (shoulder). ${ }^{42,43}{ }^{b}$ TDDFT $\mathrm{n} \rightarrow \pi^{*}$ transitions (with $f \geq 0.0001)$ : ( $\mathrm{ZnP}) 5.50(0.0074), 5.66$ ( $f=0.0012) ;\left(\mathrm{ZnPF}_{8}\right) 5.46(0.0041), 5.50(0.0001) ;\left(\mathrm{ZnPCl}_{8}\right) 5.08(0.0008), 5.09(0.0005) ;(\mathrm{ZnPBr} 8)$ $5.08(0.0041), 5.09(0.0001){ }^{c}$ TDHF-INDO/S energies with oscillator strength larger 0.001 .

TABLE 2: Excitation Energies (eV) and Oscillator Strengths $(f)$ for Zinc meso-Tetraphenylporphyrins

\begin{tabular}{|c|c|c|c|c|c|c|c|c|c|c|}
\hline \multirow[b]{2}{*}{ system/transition } & \multicolumn{3}{|c|}{ excitation energy $^{a}$} & \multicolumn{3}{|c|}{$\operatorname{shift}^{b}$} & \multicolumn{3}{|c|}{$f$} & \multirow[b]{2}{*}{ assignmen } \\
\hline & TDDFT & TDHF & $\exp$ & TDDFT & TDHF & $\exp$ & TDDFT & TDHF & $\exp$ & \\
\hline \multicolumn{11}{|l|}{ ZnTPP } \\
\hline $1^{1} \mathrm{E}$ & 2.30 & 1.65 & $2.12^{c}$ & 0.14 & 0.10 & 0.06 & 0.0158 & 0.0021 & $0.088^{c}$ & Q \\
\hline $2^{1} \mathrm{E}$ & 3.25 & 2.80 & $2.97^{c}$ & 0.29 & 0.24 & 0.16 & 1.1873 & 1.6486 & $1.39^{c}$ & B \\
\hline $3^{1} \mathrm{E}$ & 3.45 & & $3.57^{c}$ & & & & 0.1602 & & & 1 \\
\hline \multicolumn{11}{|l|}{$\mathrm{ZnTPPF}_{8}$} \\
\hline $1^{1} \mathrm{E}_{\mathrm{u}}$ & 2.39 & 1.65 & $2.15^{d}$ & 0.05 & 0.10 & 0.03 & 0.0077 & 0.0145 & & Q \\
\hline $3^{1} \mathrm{E}_{\mathrm{u}}$ & 3.46 & 2.83 & $3.02^{d}$ & 0.08 & 0.21 & 0.11 & 1.2866 & 1.6629 & & B \\
\hline $2^{1} \mathrm{E}_{\mathrm{u}}$ & 3.30 & & & & & & 0.0692 & & & \\
\hline \multicolumn{11}{|l|}{$\mathrm{ZnTPPCl}_{8}$} \\
\hline $1^{1} \mathrm{E}$ & 2.08 & 1.49 & $1.92^{e}$ & 0.36 & 0.26 & 0.26 & 0.0460 & 0.0332 & & Q \\
\hline $2^{1} \mathrm{E}$ & 2.91 & 2.61 & $2.72^{e}$ & 0.63 & 0.43 & 0.41 & 0.8449 & 1.4315 & & B \\
\hline $4^{1} \mathrm{E}$ & 3.07 & & & & & & 0.0823 & & & 1 \\
\hline \multicolumn{11}{|l|}{$\mathrm{ZnTPPBr}_{8}$} \\
\hline $1^{1} \mathrm{E}$ & 2.00 & 1.44 & $1.89^{f}$ & 0.44 & 0.31 & 0.29 & 0.0546 & 0.0410 & $0.07^{f}$ & Q \\
\hline $2^{1} \mathrm{E}$ & 2.80 & 2.54 & $2.66^{f}$ & 0.74 & 0.50 & 0.47 & 0.7790 & 1.3989 & $0.96^{f}$ & B \\
\hline $4^{1} \mathrm{E}$ & 2.97 & & & & & & 0.0991 & & & 1 \\
\hline
\end{tabular}

${ }^{a}$ TDDFT higher frequency bands (with $\left.f \geq 0.0001\right)$. ZnTPP: $3.69\left(5^{1} \mathrm{E}, 0.0367\right), 3.99\left(8^{1} \mathrm{E}, 0.0250\right), 4.01\left(9^{1} \mathrm{E}, \mathrm{z}, 0.0009\right) . \mathrm{ZnTPPF}_{8}: 3.56$ $\left(1^{1} \mathrm{~A}_{2 \mathrm{u}}, 0.0004\right) . \mathrm{ZnTPPCl}_{8}$ : $3.20\left(5^{1} \mathrm{E}, 0.0025\right) . \mathrm{ZnTPPBr}_{8}$ : $3.02\left(5^{1} \mathrm{E}, 0.0043\right)$. For TDHF-INDO/S, only energies with oscillator strength larger 0.001 are included. Additional TDHF higher frequency bands: (ZnTPP) 3.68 (z, 0.003); $\left(\mathrm{ZnTPPF}_{8}\right) 3.78(\mathrm{z}, 0.0011) ;\left(\mathrm{ZnTPPCl}_{8}\right) 3.52(\mathrm{z}, 0.0673)$; $\left(\mathrm{ZnTPPBr}_{8}\right) 3.43$ (z, 0.0909), 3.81 (z, 0.0716). ${ }^{b}$ Computed (experimental) energy shifts relative to excitation energies of $\mathrm{ZnP}\left(\mathrm{in} \mathrm{CH}{ }_{3} \mathrm{OH}\right) .{ }^{c} \mathrm{From}$ optical spectra in $\mathrm{CH}_{2} \mathrm{Cl}_{2}$ at $25{ }^{\circ} \mathrm{C} .{ }^{35}$ Spectral maxima in vapor phase at $445{ }^{\circ} \mathrm{C}$ are $2.09(\mathrm{Q}), 3.05(\mathrm{~B})$, and $3.65(1) .{ }^{35} \mathrm{Spectral}$ maxima in $\mathrm{C}_{6} \mathrm{H}_{6}$ are $2.12(\mathrm{Q}, f=0.088)$ and $2.93 \mathrm{eV}(\mathrm{B}, f=1.39) .{ }^{44,45,53}{ }^{d}$ From optical spectra in $\mathrm{CHCl}_{3},{ }^{5}$ in $\mathrm{CH}_{2} \mathrm{Cl}_{2}(2.16$ and $3.05 \mathrm{eV}) .{ }^{36}{ }^{e}$ From optical spectra in $\mathrm{CHCl}_{3} \cdot{ }^{54}{ }^{f}$ From optical spectra in $\mathrm{CH}_{2} \mathrm{Cl}_{2} \cdot{ }^{3}$

therefore, may also have resulted in better agreement between experiment and the TDHF-INDO/S results. The TDDFT and TDHF-INDO/S oscillator strengths of the Q and B bands are in good agreement with one another and with experiment. The next state, $3{ }^{1} \mathrm{E}_{\mathrm{u}}\left(2 \mathrm{~b}_{2 \mathrm{u}} \rightarrow 5 \mathrm{e}_{\mathrm{g}}\right)$, is located at $3.84 \mathrm{eV}$ with an oscillator strength of 0.05 . This state is assigned to the weak band on the high-energy side of the B band, which appears at
$3.29 \mathrm{eV}$ in the $\mathrm{ZnP}$ spectrum in methanol. This band appears at $3.35 \mathrm{eV}$ in the spectrum taken in $n$-octane and is a shoulder at $\sim 3.3 \mathrm{eV}$ in the spectrum recorded in benzene. ${ }^{43}$ The $3^{1} \mathrm{E}_{\mathrm{u}}\left(2 \mathrm{~b}_{2 \mathrm{u}}\right.$ $\rightarrow 5 \mathrm{e}_{\mathrm{g}}$ ) state has been previously assigned to the $\mathrm{N}$ band based upon the $\pi \mathrm{MO}$ and INDO/S CI results. ${ }^{38,39}$ The TDHF-INDO/S spectrum of $\mathrm{ZnP}$ does not have transitions with significant oscillator strengths in the energy region between the $\mathrm{B}$ and $\mathrm{N}$ 


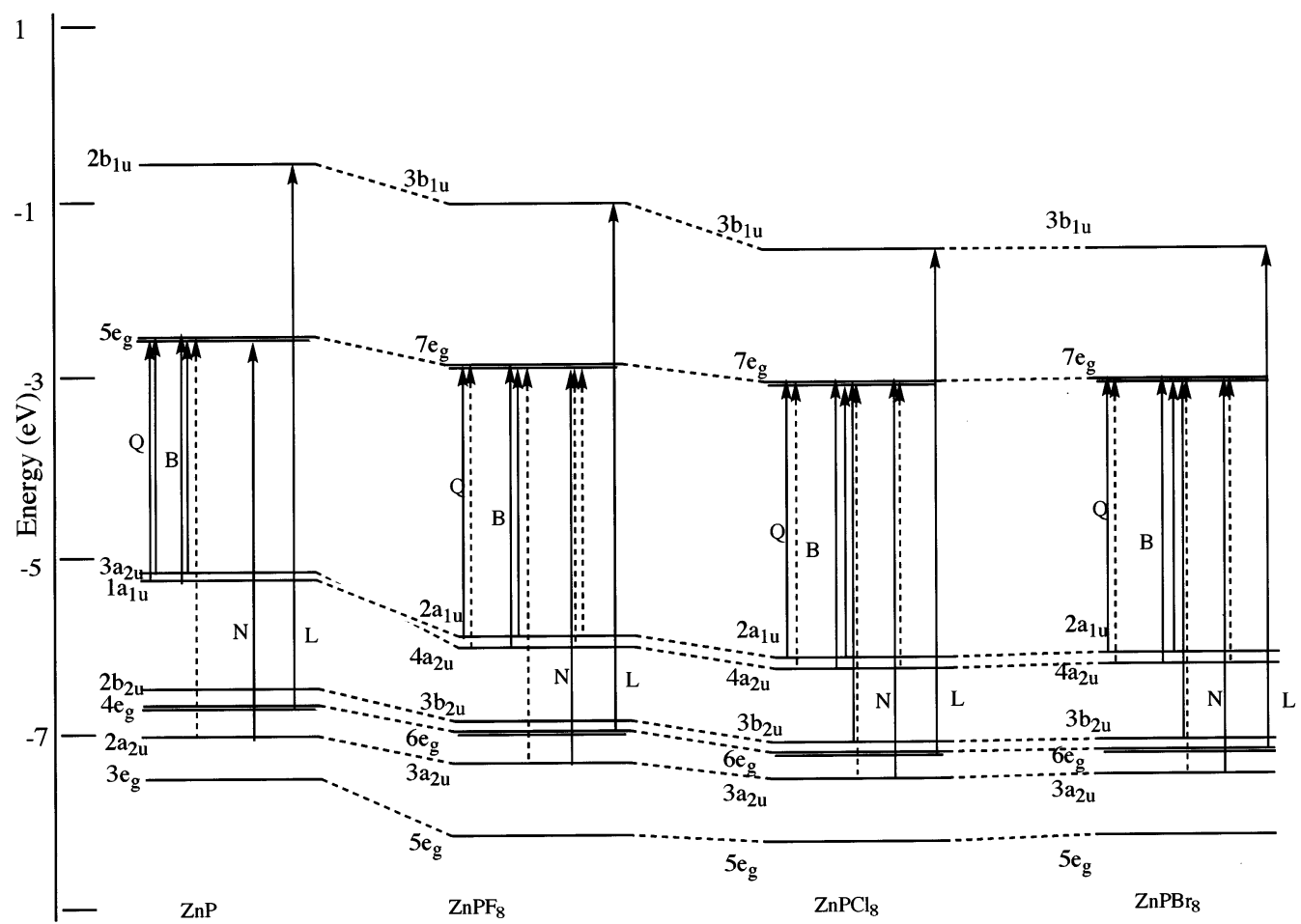

Figure 2. Molecular orbital diagrams summarizing the TDDFT predicted transitions for zinc porphyrin (ZnP) and their halogenated derivatives $\left(\mathrm{ZnPX}_{8}\right)$. Solid arrows represent the major and minor contributions, respectively. Contour plots of the occupied and virtual orbitals of $\mathrm{ZnP}$ and $\mathrm{ZnPX}_{8}$ and their orbital energies are given in the Supporting Information.

bands. For the $\mathrm{N}\left[4^{1} \mathrm{E}_{\mathrm{u}}\left(2 \mathrm{a}_{2 \mathrm{u}} \rightarrow 5 \mathrm{e}_{\mathrm{g}}\right)\right]$ and $\mathrm{L}\left[5^{1} \mathrm{E}_{\mathrm{u}}\left(4 \mathrm{e}_{\mathrm{g}} \rightarrow 2 \mathrm{~b}_{1 \mathrm{u}}\right)\right]$ bands of ZnP, TDDFT overestimates the excitation energies in methanol by 0.22 and $0.31 \mathrm{eV}$, respectively. TDHF-INDO/S overestimates the $\mathrm{N}$ band by $0.23 \mathrm{eV}$ but underestimates the $\mathrm{L}$ band by $0.18 \mathrm{eV}$. The next band, $\mathrm{M}\left[6^{1} \mathrm{E}_{\mathrm{u}}\left(1 \mathrm{~b}_{1 \mathrm{u}} \rightarrow 5 \mathrm{e}_{\mathrm{g}}\right)\right]$, located at $6.04 \mathrm{eV}$ with TDDFT, is significantly higher than the experimental value of $5.50 \mathrm{eV}$. TDHF-INDO/S predicts an excitation of $5.24 \mathrm{eV}$ for the $\mathrm{M}$ band in good agreement with experiment.

Contour plots of electronic modes of $\mathrm{ZnP}$ are shown in the left column of Figure 4. Each row represents a transition (Q, B, N, L, M). Similar transition density matrixes were observed in the free-base and magnesium porphyrins. ${ }^{10}$ The figure immediately reveals the nature of each transition. The $\mathrm{Q}$ mode of $\mathrm{ZnP}$ is dominated by the diagonal as well as near-diagonal elements of the bridge carbons 5-7, 11-13, 17-19, and 231. The $\mathrm{Q}$ electronic modes are almost symmetric with respect to the diagonal. This reflects the absence of preferable direction of motion for holes or electrons. This is no longer the case for the Soret (B) transition whose electronic modes are shown in the second row in Figure 4. Here all modes have the same structure: they are delocalized over the entire molecule and stretched along the $y$ (electron) direction, reflecting the chargetransfer character of the Soret band. In addition, each B transition is dominated by a specific charge transfer process (blue elements). The preferable process is the electron transfer from the bridge carbons $6,12,18$, and 24 to other parts of the molecule. The $\mathrm{N}$ transitions are localized on the two vertical "strips" and describe electron transfer from the pyrrole rings IV (left strip) and II (right strip) to the entire molecule. The L modes are similar to $\mathrm{N}$. However, they describe electron delocalization from pyrroles I and III to the entire molecule. Finally the $M$ transition involves the carbon atoms in pyrroles IV and II (7, 9 10, 11, and 19, 21, 22, 23). It is delocalized over the entire molecule. However the participation of $\beta$-halo- gens is very weak and becomes more pronounced with heavier substituents.

The effects of $\beta$-halogen groups on the $1^{1} \mathrm{E}_{\mathrm{u}}$ and $2^{1} \mathrm{E}_{\mathrm{u}}$ states of $\mathrm{ZnP}$ have been examined previously. ${ }^{7,8}$ The halogenation of $\mathrm{ZnP}$ at the $\beta$ positions resulted in a slight blue shift of the $\mathrm{Q}$ band $\left(1^{1} \mathrm{E}_{\mathrm{u}}\right)$ by the fluoro groups, whereas chloro and bromo auxochromes slightly shift it to the red. For $\mathrm{ZnPX}_{8}$, the $2^{1} \mathrm{E}_{\mathrm{u}}$ state is not the dominant band. This band is primarily made of the $3 \mathrm{~b}_{2 \mathrm{u}} \rightarrow 7 \mathrm{e}_{\mathrm{g}}$ excitation that is analogous to the $3{ }^{1} \mathrm{E}_{\mathrm{u}}\left(2 \mathrm{~b}_{2 \mathrm{u}} \rightarrow\right.$ $5 e_{\mathrm{g}}$ ) state of $\mathrm{ZnP}$ (see Figure 2). $\beta$-Halogenation results in large red shifts with increasing magnitude upon going down the periodic table (up to 0.36 and $0.66 \mathrm{eV}$ relative to the $2^{1} \mathrm{E}_{\mathrm{u}}(\mathrm{B}$ band) and $3^{1} \mathrm{E}_{\mathrm{u}}$ states of $\mathrm{ZnP}$, respectively, for the bromo groups). The $\mathrm{B}$ bands of $\mathrm{ZnPX}_{8}$ are assigned to the $3^{1} \mathrm{E}_{\mathrm{u}}$ state that is slightly blue shifted $(0.1 \mathrm{eV})$ upon fluorination. Chlorination and bromination red shift the $\mathrm{B}$ band of $\mathrm{ZnP}$ by 0.10 and $0.17 \mathrm{eV}$, respectively. These spectral shifts predicted by TDDFT are not reproduced by the TDHF-INDO/S calculations (see Table 1). For example, the largest TDHF-INDO/S shift of only $0.06 \mathrm{eV}$ predicted for the $\mathrm{B}$ band of $\mathrm{ZnPBr}_{8}$ is much smaller than the corresponding TDDFT shift. For the $\mathrm{N}$ band, the halogen substituents are predicted to lower the excitation energy of $\mathrm{ZnP}$ by $0.5-0.8 \mathrm{eV}$ but do not change its intensity significantly. TDHF-INDO/S predicts the $\mathrm{N}$ band of $\mathrm{ZnP}$ to red shift by $0.2-0.3 \mathrm{eV}$ upon halogenation. For the $\mathrm{L}$ band, large red shifts induced by chlorination $(0.54 \mathrm{eV})$ and bromination $(0.67 \mathrm{eV})$ are predicted by TDDFT. The corresponding TDHFINDO/S red shifts are about $0.3 \mathrm{eV}$. Upon halogenation, the high-frequency $\mathrm{M}$ transition is slightly $(\sim 0.1 \mathrm{eV})$ red shifted, as predicted by TDHF-INDO/S. This is in good agreement with the TDDFT result for $\mathrm{ZnPF}_{8}$ but not for $\mathrm{ZnPCl}_{8}$. These trends can be rationalized by examining the right three columns in Figure 4, which show the corresponding electronic modes. We note that the substituted $X$ atoms (25-32) do not play the major role in the Q, B, and $\mathrm{M}$ transitions. However the halogens (27, 


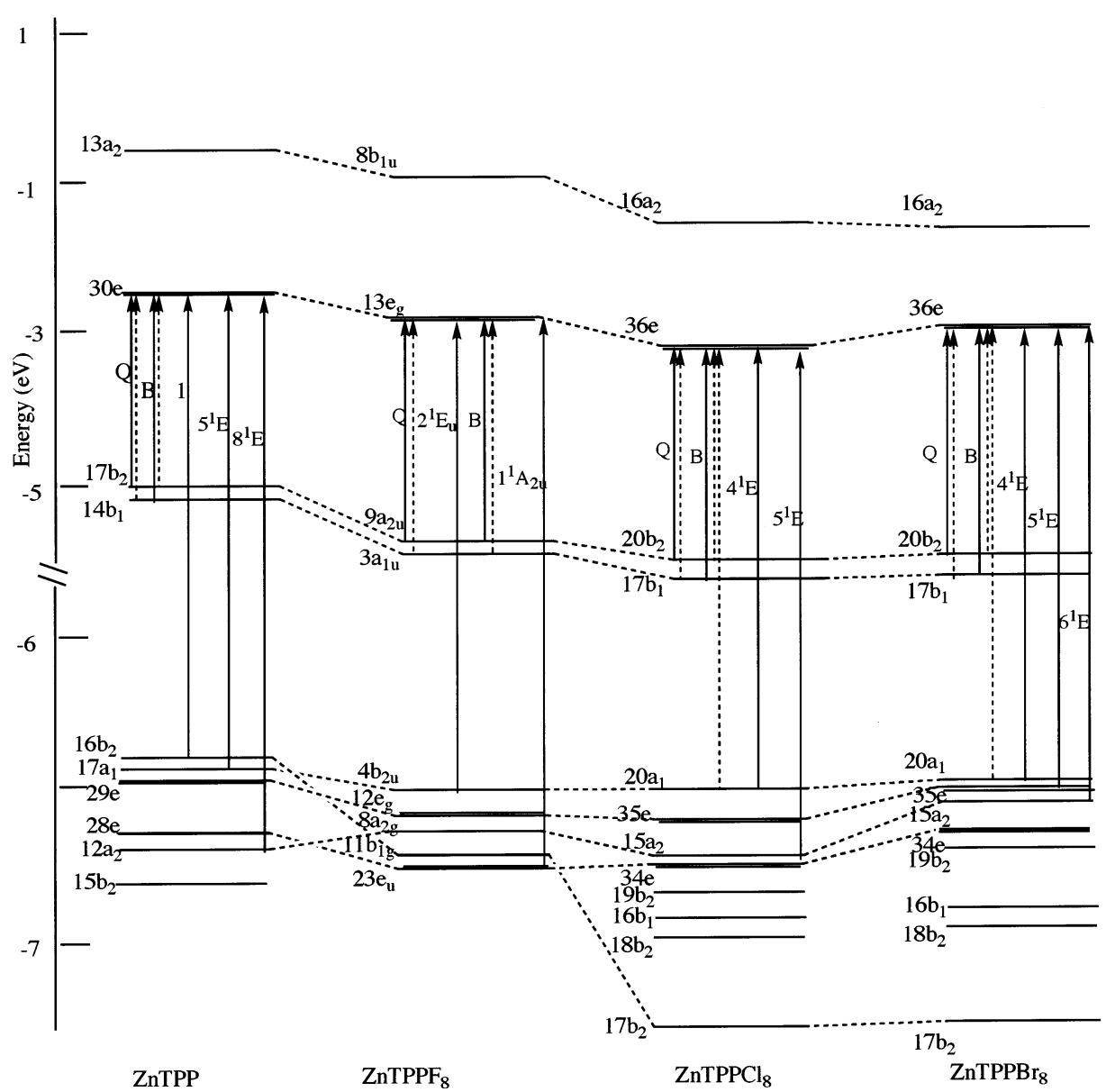

Figure 3. Molecular orbital diagrams summarizing the TDDFT predicted transitions for zinc tetraphenylporphyrin (ZnTPP) and their halogenated derivatives $\left(\mathrm{ZnTPPX}_{8}\right)$. Solid arrows represent the major and minor contributions, respectively. Contour plots of the occupied and virtual orbitals of $\mathrm{ZnTPP}$ and $\mathrm{ZnTPPX}_{8}$ and their orbital energies are given in the Supporting Information.

28 and 31, 32) strongly participate in $\mathrm{L}$ and $\mathrm{N}$ excitations due to dramatic charge redistribution in the II and IV pyrroles. In contrast, the KS orbitals (see Figure $2 \mathrm{~S}$ in the Supporting Information) that participate in all the transitions $(\mathrm{Q}, \mathrm{B}, \mathrm{N}, \mathrm{L}$, and $\mathrm{M}$ ) for $\mathrm{ZnPX}_{8}$ receive a significant contribution from the halogens.

2. ZnTPP and ZnTPPX . The substitution of four meso hydrogens with phenyl groups in $\mathrm{ZnP}$ gives rise to the slight saddle structure for ZnTPP, a change from $D_{4 h}$ to $D_{2 d}$ symmetry. ${ }^{8}$ The electron-donating phenyl groups destabilize the HOMO $\left(17 b_{2}\right)$ and, to a lesser extent, the HOMO-1 (14b 1 ) but leave the degenerate LUMO essentially unchanged (Figure 3). Therefore, the Q and B bands of ZnTPP are expected to be red shifted compared to those of ZnP. Experimentally, the red shifts of 0.06 and $0.16 \mathrm{eV}$ are observed in dichloromethane relative to the $\mathrm{ZnP}$ spectrum in methanol for the $\mathrm{Q}$ and $\mathrm{B}$ bands, respectively (see Table 2). Interestingly, an identical shift in a common benzene solvent is observed for the B band, whereas a slightly larger $(0.09 \mathrm{eV})$ value is observed for the $\mathrm{Q}$ band in the same solvent. TDDFT predicts the red shifts of 0.14 (Q band) and 0.29 (B band) $\mathrm{eV}$ upon tetraphenylation. The corresponding TDHF-INDO/S red shifts are 0.10 and $0.24 \mathrm{eV}$. The computed TDHF-INDO/S shifts for the low-frequency $\mathrm{Q}$ and $\mathrm{B}$ bands compare well with experiment and TDDFT. However, the computed excitation energies of $\mathrm{Q}$ and $\mathrm{B}$ bands for ZnTPP deviate from the gas-phase $\left(\mathrm{CH}_{2} \mathrm{Cl}_{2}\right)$ experiment by $-0.44(-0.47)$ and $-0.25(-0.17) \mathrm{eV}$ for the TDHF-INDO/S compared with $+0.21(+0.18)$ and $+0.20(+0.28) \mathrm{eV}$ for the TDDFT. The low-frequency intensities of the two $\mathrm{ZnP}$ and
ZnTPP families are very similar. The experimental oscillator strengths of $0.088^{44}$ and $0.0105^{45}$ for the $\mathrm{Q}$ band have been measured in benzene. The former value has been corrected for the refractive index factor. The computed TDDFT (0.016) and TDHF-INDO/S (0.002) values are in better agreement with the uncorrected value than the corrected one. For the B band of ZnTPP, the predicted TDDFT and TDHF-INDO/S values of 1.19 and 1.65 , respectively, are consistent with the experimental value of 1.39 (corrected for the refractive index factor). In comparison to $\mathrm{ZnP}$, the computed oscillator strengths of the $\mathrm{B}$ band slightly increase upon tetraphenyl substitution, in agreement with experiment. However, the oscillator strengths (noncorrected) obtained in different solvents might vary significantly. ${ }^{4}$ Therefore, caution must be taken when comparing oscillator strengths in different solvents.

The next band occurs between the B and $\mathrm{N}(4.00 \mathrm{eV})$ bands at $3.65 \mathrm{eV}$ in the gas-phase spectrum of ZnTPP. This band has been labeled as the 1 band by Edward et al. ${ }^{35}$ The TDDFT spectrum in this region has a number of bands, with the most intense band at $3.45 \mathrm{eV}\left(3^{1} \mathrm{E}\right)$. The 1 band, therefore, is assigned to the $3^{1} \mathrm{E}$ state. The higher energy states $\left(5^{1} \mathrm{E}, 8^{1} \mathrm{E}\right.$, and $\left.9^{1} \mathrm{E}\right)$ with small oscillator strengths likely show up as the tails of the 1 and $\mathrm{N}$ bands. The ${ }^{1} \mathrm{E}$ state with a small transition dipole component perpendicular to the molecular plane ( $z$ polarization) is located at $4.01 \mathrm{eV}$. The corresponding TDHF-INDO/S feature with $z$ polarization is predicted to occur at about $(3.68 \mathrm{eV})$ the same energy as the observed 1 band for ZnTPP. This band is predicted to increase in intensity in $\mathrm{Cl}$ and $\mathrm{Br}$ substituted ZnTPPs that have more pronounced geometry distortion. The 

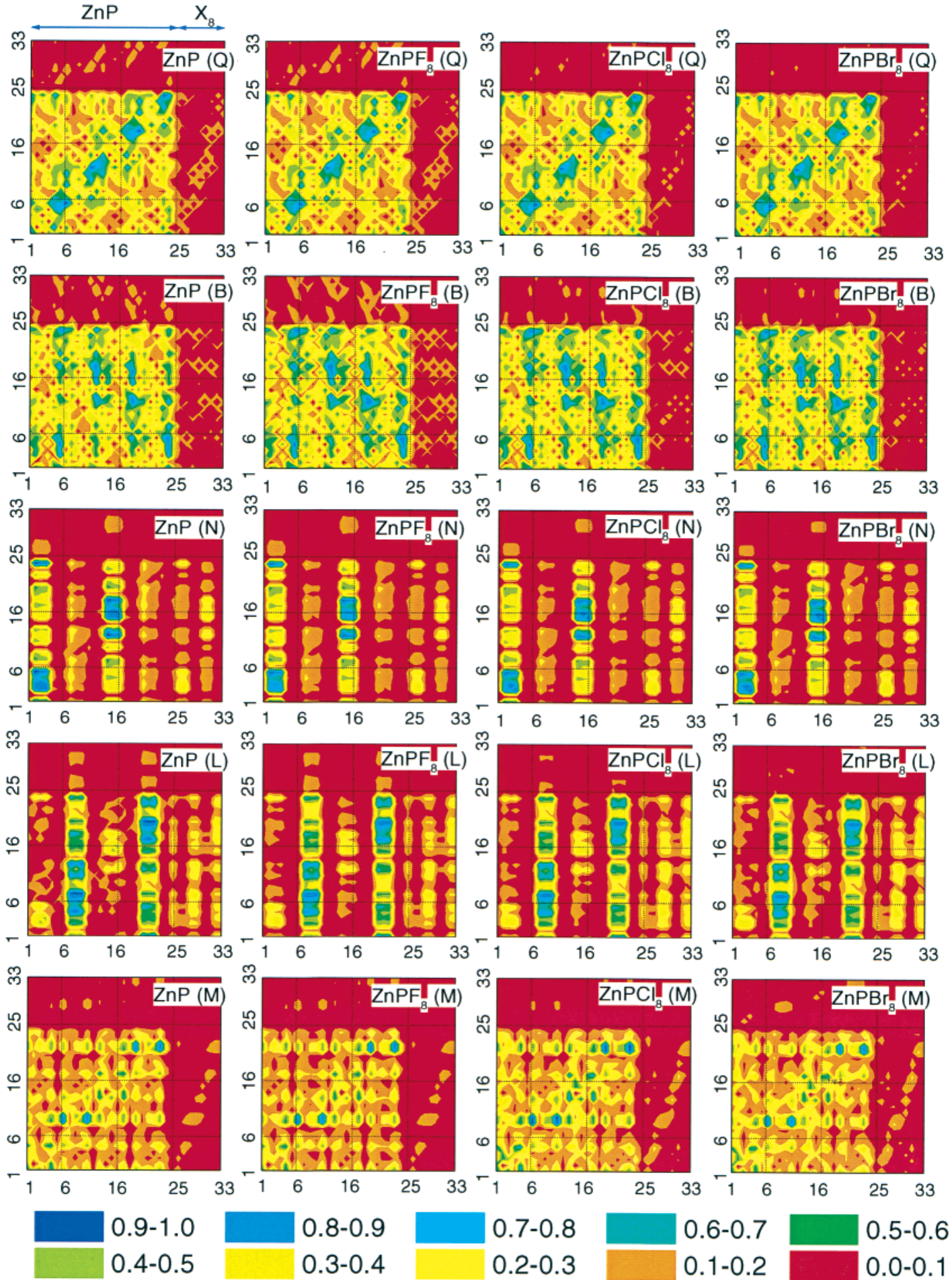

Figure 4. Contour plots of the dominant electronic modes for $\mathrm{ZnP}$ and their halogenated derivatives. The ordinate and abscissa label electron and hole, respectively.

$\mathrm{N}$, L, and M bands of ZnTPP are predicted to occur at 4.31, 4.56, and $5.27 \mathrm{eV}$, respectively. These TDHF-INDO/S transition energies deviate by $+0.25(\mathrm{~N}),-0.40(\mathrm{~L})$, and $-0.78(\mathrm{M}) \mathrm{eV}$ from the spectral maximum in the gas phase. The spectral maximum of the broad $\mathrm{M}$ band in $\mathrm{CH}_{2} \mathrm{Cl}_{2}$ is significantly red shifted $(0.61 \mathrm{eV})$ in comparison to the gas-phase maximum. In the vacuum UV spectrum of ZnTPP three intense bands have also been observed at $6.70\left(\mathrm{X}_{1}, f=3.0 \pm 0.5\right), 7.61\left(\mathrm{X}_{2}, f=\right.$ $1.0 \pm 0.5)$, and $8.24\left(\mathrm{X}_{3}, f=1.5 \pm 0.7\right) \mathrm{eV} .{ }^{35} \mathrm{TDHF}-\mathrm{INDO} / \mathrm{S}$ predicts four transitions with significant oscillator strengths to occur at around $6 \mathrm{eV}$. The two most intense transitions are largely localized on the phenyl rings. These transitions, significantly underestimated in frequency, are predicted to give rise to the broad $\mathrm{X}_{1}$ band.

Contour plots of the electronic modes for ZnTPP are shown in the left column of Figure 5. The labeling schemes are similar to the ones used for $\mathrm{ZnP}$ and $\mathrm{ZnPX}_{8}$. Each row represents a transition $(\mathrm{Q}, \mathrm{B}, \mathrm{N}, \mathrm{L}, \mathrm{M})$. The columns show molecular labels. The $\mathrm{Q}$ and $\mathrm{B}$ transitions are delocalized over the porphyrin ring and are analogous to those of $\mathrm{ZnP}$. We notice only a weak coherence trace on the phenyls. The $\mathrm{N}$ transitions are localized on the two vertical "strips". This reveals electron transfer from 

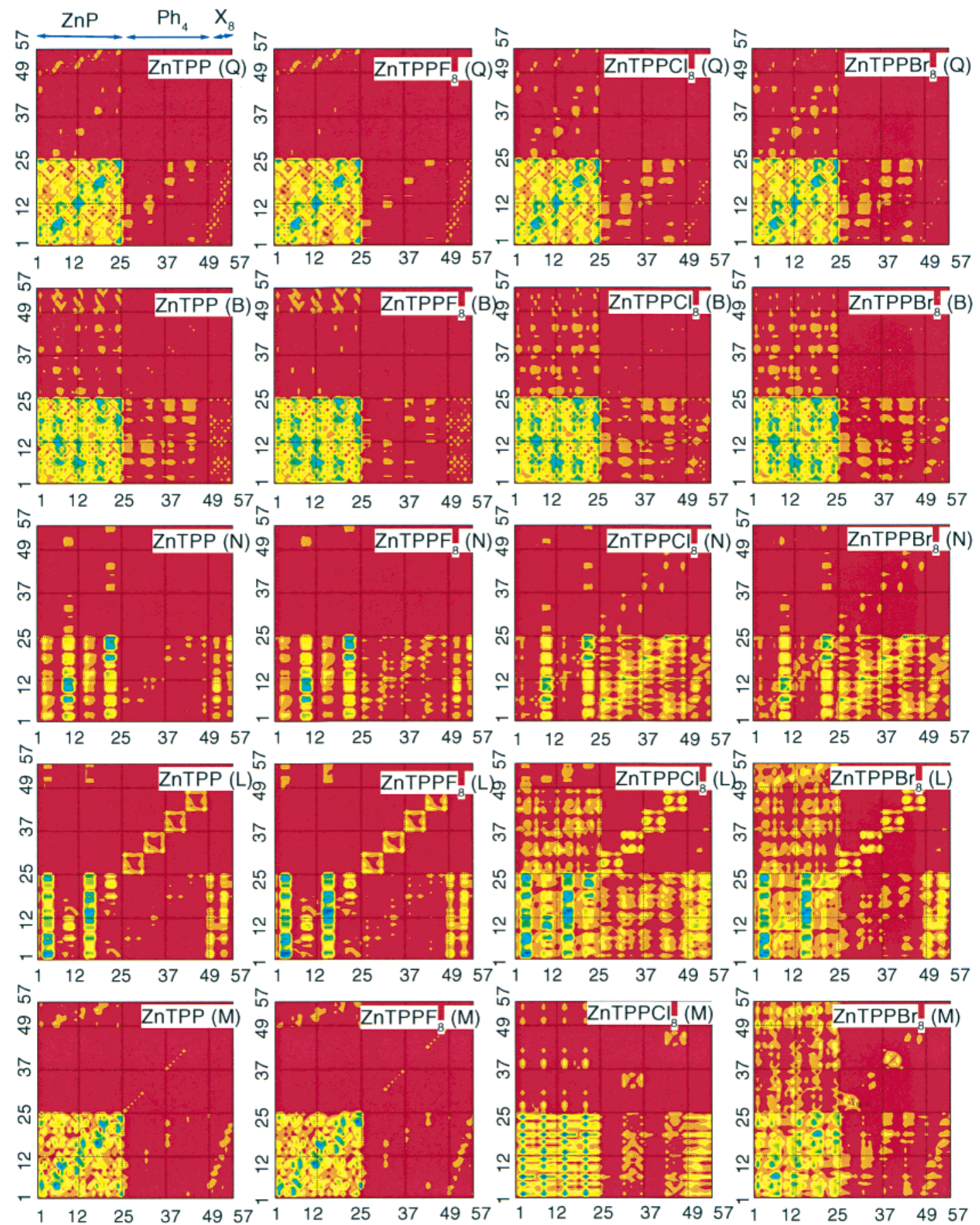

Figure 5. Contour plots of the dominant electronic modes for ZnTPP and their halogenated derivatives. The ordinate and abscissa label electron and hole, respectively.

the II and IV pyrrole rings to the rest of the porphyrin skeleton. Similar to N, the L mode (fourth row) describes electron delocalization from pyrroles I and III to the porphyrin ring. In addition, the electronic coherences are weakly involved to the phenyl rings (squares in the upper right part of the panels). The $\mathrm{M}$ mode is localized on the porphyrin ring similar to the $\mathrm{M}$ band in the $\mathrm{ZnPX}_{8}$ series (cf. Figures 4 and 5).

In comparing the absorption spectrum of ZnTPP with spectra of different $\beta$-halogen substituted derivatives, we found their calculated spectral shifts to be similar to those found in $\mathrm{ZnP}$ and $\mathrm{ZnPX}_{8}$ series. Except for the $\mathrm{X}$ band, all other absorption peaks in $\mathrm{ZnTPPCl}_{8}$ and $\mathrm{ZnTPPBr}_{8}$ are red shifted from those of $\mathrm{ZnTPP}$. The B bands of $\mathrm{ZnTPPCl}_{8}$ and $\mathrm{ZnTPPBr}_{8}$ are shifted by 0.2 and $0.3 \mathrm{eV}$, respectively (see Table 2). Their Q bands are red shifted about $0.2 \mathrm{eV}$. Note that the predicted TDHF-
INDO/S red shifts for the $\mathrm{ZnTPPCl}_{8}$ and $\mathrm{ZnTPPBr}_{8}$ are in good agreement with experiment and the TDDFT predicted trends. For $\mathrm{ZnTPPF}_{8}$, the B band is predicted to be slightly blue shifted $(0.03 \mathrm{eV})$ whereas the $\mathrm{Q}$ band remains unchanged in comparison to ZnTPP. Again, this is in qualitative agreement with experimental data and TDDFT results. The $\mathrm{N}$ bands are weak and are red shifted about $0.3-0.4 \mathrm{eV}$ for $\mathrm{ZnTPPX}_{8}$. The $\mathrm{L}$ transition is predicted to be slightly blue shifted for $\mathrm{ZnTPPF}_{8}$ and are red shifted for other $\mathrm{ZnTPPX}_{8}$. The frequencies of the $\mathrm{X}$ bands that originate from the phenyl groups are largely unaffected by $\beta$-halogenation.

The large red shifts in the Q and B bands have been attributed to the conformational distortion due to the steric interactions between the phenyl and halogen groups, which resulted in the pronounced saddle structures for $\mathrm{ZnTPPBr}_{8} \cdot{ }^{3}$ However, the total 
TABLE 3: Different Contributions of TDDFT Excitation Energies $(E, \mathrm{eV})$ for Zinc Porphyrins ${ }^{a}$

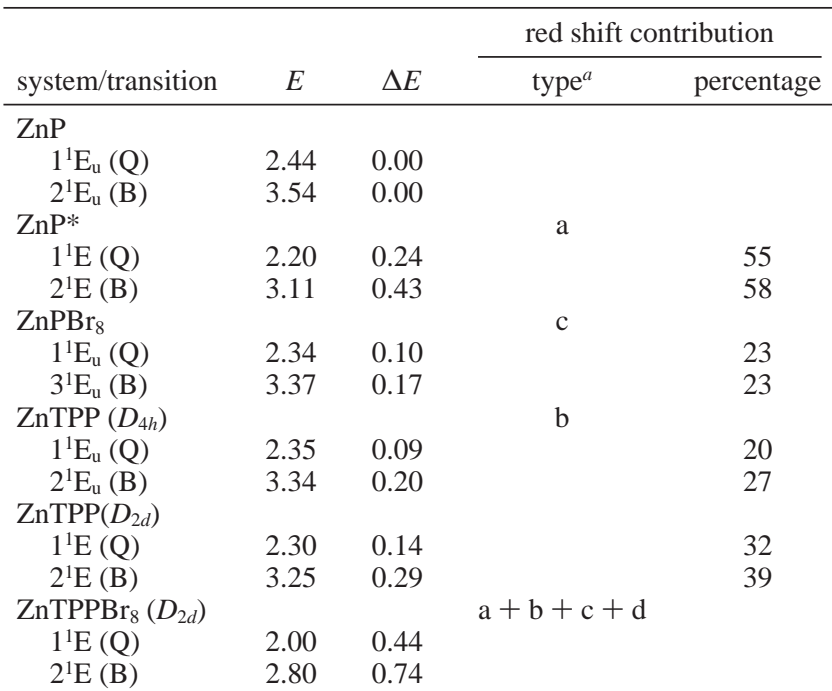

${ }^{a}$ (a) Conformational distortion, (b) the meso-phenyl groups, (c) the $\beta$-bromo groups, and (d) combined effects of nonplanar distortion, mesotetraphenylation, and $\beta$-octabromination.

spectral red shift for a given band of $\mathrm{ZnTPPBr}_{8}$ consists of contributions from (a) conformational distortion, (b) the mesophenyl groups, (c) the $\beta$-bromo groups, and (d) combined effects of nonplanar distortion, meso-tetraphenylation, and $\beta$-octabromination. Analysis of the shifts suggests that geometry distortion, which facilitates the interactions among the porphyrin ring, halogens, and phenyls plays an important role. In our previous work, the red shifts induced by nonplanar distortion for the first and second excited states of $\mathrm{ZnTPPBr}_{8}$ were underestimated due to neglecting the effect of meso-tetraphenylation. ${ }^{8,46}$ Table 3 reports the contributions from (a), (b), and (c) to the total red shifts of first and second excited states (which is not necessarily the same as the $\mathrm{Q}$ and $\mathrm{B}$ bands) of $\mathrm{ZnTPPBr}_{8}$. For example, the $\mathrm{B}$ band of $\mathrm{ZnPBr}_{8}$ is assigned to the $3^{1} \mathrm{E}_{\mathrm{u}}$ state. For the $\mathrm{Q}$ band, $\beta$-octabromination contributes $23 \%$ of total red shifts of $\mathrm{ZnTPPBr}_{8}$ relative to $\mathrm{ZnP}$. In addition, the red shift induced by meso-tetraphenylation alone accounts for $20 \%$ of the total red shift. This is consistent with the $55 \%$ red shift contribution from nonplanar distortion, as calculated from the modified $\mathrm{ZnTPPBr}_{8}$ structure $\left(\mathrm{ZnP}^{*}\right)$ with all the bromo and phenyl substituents being replaced by hydrogens, while the distorted porphyrin skeleton is retained. This (or any other artificially distorted structure) is not a unique choice but is the most logical choice in quantifying the contribution of distortion. Different choices of artificially constrained structures are likely to give different results. Note that the red shift induced by meso-tetraphenylation is calculated from the $D_{4 h}$ structure of ZnTPP. The red shift upon going from $\mathrm{ZnP}$ to the $D_{2 d}$ structure of $\mathrm{ZnTPP}$ is larger due to its slightly saddled structure with the opposite phenyl rings gauche by $11^{\circ}$. Note that the sum of (a), (b), and (c) is almost identical to the total red shift due to a small contribution from (d). Similarly, our analysis of $\beta$-octabromination and mesotetraphenylation effects on the B band gives a $50 \%$ contribution to total red shift in $\mathrm{ZnTPPBr}_{8}$. The remaining half can be approximately attributed to distortion, which is in good agreement with the $58 \%$ contribution calculated from $\mathrm{ZnP} *$.

The TDHF-INDO/S shifts are consistent with corresponding TDDFT shifts for the $\mathrm{Q}$ bands but are slightly off $(0.1 \mathrm{eV})$ for the B bands. The red shifts predicted by TDHF-INDO/S for the $\mathrm{N}$ and $\mathrm{L}$ bands for the chlorination and bromination of ZnTPP are even larger. Analysis of the shifts suggests that geometry distortion that facilitates the interactions among the porphyrin ring, halogens, and phenyls also plays an important role.

For the Q and B electronic transitions, the phenyl carbons (25-48) and halogens (49-57) only weakly participate in optical excitations. The magnitudes of coherences on these atoms are about 10 times smaller (yellow elements) compared to the core porphyrin. This is reflected in the $0.1-0.2 \mathrm{eV}$ red shift observed in the spectra. The Q modes of $\mathrm{ZnTPP}$ and $\mathrm{ZnTPPF}_{8}$ are very similar (first row). We notice only a weak coherence trace on the phenyls and halogens. Due to the conformational disorder the Q modes of $\mathrm{ZnTPPCl}_{8}$ and $\mathrm{ZnTPPBr}_{8}$ have slightly larger coherences on the phenyls and halogens, which cause the red shift of excitation energies. The same trends are observed in the B transition (second row). However, the electronic coherences of the B band on the phenyl and halogen groups are more pronounced and lead to larger red shifts in spectra of $\mathrm{ZnTPPCl}_{8}$ and $\mathrm{ZnTPPBr}_{8}$. The halogens $(51,52$ and 55, 56) participate in the $\mathrm{N}$ excitation due to dramatic charge redistribution in the pyrroles II and IV. Looking along the $\mathrm{N}$ panels (third row) we notice that halogen substitution dramatically extends electronic coherences to phenyl carbons, especially for ZnTP$\mathrm{PCl}_{8}$ and $\mathrm{ZnTPPBr}_{8}$. These coherences (lower right part of the panels) describe an electron-transfer process from the phenyls to the porphyrin ring through the pyrroles that is induced by distortion. Similar to the $\mathrm{N}$ mode, halogens participate in the $\mathrm{L}$ transition (lower right part of the panels). There is no electronic delocalization (nonzero off-diagonal elements) between the porphyrin ring and phenyl groups in ZnTPP and $\mathrm{ZnTPPF}_{8}$, whereas significant electronic delocalization is observed between the porphyrin ring and phenyl groups in $\mathrm{ZnTPPCl}_{8}$ and $\mathrm{ZnTPPBr}_{8}$. Again steric effects cause additional electronic coherences between the phenyl group and the porphyrin ring in $\mathrm{ZnTPPCl}_{8}$ and $\mathrm{ZnTPPBr}_{8}$.

\section{Summary and Conclusions}

The spectra of zinc porphyrin, zinc meso-tetraphenylporphyrin, and their $\beta$-halogenated derivatives have been predicted and analyzed to obtain the origin of the spectral shifts in color and intensity. $\beta$-halogenation and meso-phenylation of zinc porphyrin generally shifts the ground-state excitation energies to the red. The large red shifts experimentally observed for the Q and $\mathrm{B}$ bands in $\mathrm{ZnTPPCl}_{8}$ and $\mathrm{ZnTPPBr}_{8}$ can be attributed to the combination of geometry distortion and phenyl and halogen groups. Larger red shifts are also predicted for the $\mathrm{N}$ and $\mathrm{L}$ bands upon chlorination and bromination of ZnTPP. The highfrequency bands are identified and analyzed in the TDHF-

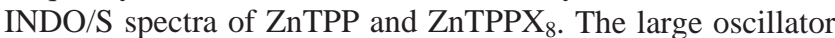
strengths computed for ZnTPP in the high-energy region are consistent with the $\mathrm{X}_{1}$ band in the experimental spectrum. The spectral trends predicted by TDHF-INDO/S are largely consistent with available TDDFT and experimental results. TDDFT predicts small spectral shifts for the $\mathrm{ZnPX}_{8}$ series that are not reproduced by TDHF-INDO/S. Overall the spectral trends predicted by TDHF-INDO/S are largely consistent with available TDDFT and experimental results, with a greatly reduced computational cost. TDDFT calculation for a single system, for example ZnTPP, took more than 3 days (wall-clock time) using 8 nodes on the IBM-SP3 to solve 50 roots. The TDDFT computations of higher lying electronic states, requiring a much larger number of roots to be solved, are quite demanding in CPU and memory. On the other hand, the corresponding semiempirical calculations took approximately $2 \mathrm{~h}$ on a single node and can be done on desktop PCs due to the low-memory 
requirement. This enables spectral studies of very large systems such as light harvesting complex II of purple bacteria that consists of 24 porphyrins and 8 carotenoids, or relevant nonlinear absorbing chromophores. ${ }^{47-50}$ In addition, the TDHFINDO/S approach can be readily applied to study the excitedstate potential surface parameters using the excited-state molecular dynamics approach, ${ }^{51,52}$ which is currently impractical with the TDDFT for such molecular sizes.

Supporting Information Available: Tables of orbital energies and computed TDHF-INDO/S excitation energies and oscillator strengths for high-energy transitions for ZnTPP and $\mathrm{ZnTPPX}_{8}$. Contour plots of the occupied and virtual orbitals of $\mathrm{ZnP}, \mathrm{ZnPX}_{8}, \mathrm{ZnTPP}$, and $\mathrm{ZnTPPX}_{8}$. This material is available free of charge via the Internet at http://pubs.acs.org.

\section{References and Notes}

(1) Dolphin, D.; Traylor, T. G.; Xie, L. Y. Acc. Chem. Res. 1997, 30, 251

(2) Su, W.; Cooper, T. M.; Brant, M. C. Chem. Mater. 1998, 10, 1212.

(3) Bhyrappa, P.; Krishnan, V. Inorg. Chem. 1991, 30, 239.

(4) Bhyrappa, P.; Krishnan, V.; Nethaji, M. J. Chem. Soc., Dalton Trans. 1993, 1901.

(5) Leroy, J.; Bondon, A.; Toupet, L.; Rolando, C. Chem. Eur. J. 1997, 3,1890 .

(6) Dolphin, D. H.; Nakano, T.; Kirk, T. K.; Maione, T. E.; Farrell, R. L.; Wijiesekera, T. P. Octachloro tetraphenylporphyrin. Chem. Abstr. 1989, 111, 7144u; PCT Int Appl. 1988; Vol. WO 88 07; pp 988.

(7) Nguyen, K. A.; Day, P. N.; Pachter, R. J. Chem. Phys. 1999, 110 , 9135.

(8) Nguyen, K. A.; Day, P. N.; Pachter, R. J. Phys. Chem. 1999, 103, 7378.

(9) Baker, J. D.; Zerner, M. C. Chem. Phys. Lett. 1990, 175, 192.

(10) Tretiak, S.; Chernyak, V.; Mukamel, S. Chem. Phys. Lett. 1998, 297, 357.

(11) Becke, A. D. J. Chem. Phys. 1993, 98, 5648.

(12) Becke, A. D. Phys. Rev. A 1988, 38, 3098.

(13) Lee, C.; Yang, W.; Parr, R. G. Phys. Rev. B 1988, 37, 785. 6026.

(14) Stevens, W. J.; Basch, H.; Krauss, M. J. Chem. Phys. 1984, 81,

(15) Stevens, W. J.; Basch, H.; Krauss, M.; Jasien, P. Can. J. Chem. 1992, 70,612 .

(16) Bauernschmitt, R.; Ahlrichs, R. Chem. Phys. Lett. 1996, 256, 454.

(17) Casida, M.; Jamorski, C.; Casida, K. C.; Salahub, D. R. J. Chem. Phys. 1998, 108, 4439.

(18) Stratmann, R. E.; Scuseria, G. E.; Frisch, M. J. J. Chem. Phys. 1998, 109, 8218.

(19) Frisch, M. J.; Trucks, G. W.; Schlegel, H. B.; Scuseria, G. E.; Robb, M. A.; Cheeseman, J. R.; Zakrzewski, V. G.; Montgomery, J. A.; Stratmann, R. E.; Burant, J. C.; Dapprich, S.; Millam, J. M.; Daniels, A. D.; Kudin, K. N.; Strain, M. C.; Farkas, O.; Tomasi, J.; Barone, V.; Cossi, M.; Cammi, R.; Mennucci, B.; Pomelli, C.; Adamo, C.; Clifford, S.; Ochterski, J.; Petersson, G. A.; Ayala, P. Y.; Cui, Q.; Morokuma, K.; Malick, D. K.; Rabuck, A. D.; Raghavachari, K.; Foresman, J. B.; Cioslowski, J.; Ortiz, J. V.; Stefanov, B. B.; Liu, G.; Liashenko, A.; Piskorz, P.; Komaromi, I.; Gomperts, R.; Martin, R. L.; Fox, D. J.; Keith, T.; Al-Laham, M. A.; Peng, C. Y.; Nanayakkara, A.; Gonzalez, C.; Challacombe, M.; Gill, P. M. W.;
Johnson, B. G.; Chen, W.; Wong, M. W.; Andres, J. L.; Head-Gordon, M.; Replogle, E. S.; Pople, J. A. Gaussian 98, revision A.7; Gaussian, Inc: Pittsburgh PA, 1998.

(20) Nguyen, K. A.; Pachter, R. J. Chem. Phys. 2001, 114, 10757.

(21) Tretiak, S.; Chernyak, V.; Mukamel, S. J. Am. Chem. Soc. 1997, 119,11408 .

(22) Tretiak, S.; Chernyak, V.; Mukamel, S. J. Chem. Phys. 1996, 105, 8914.

(23) Chernyak, V.; Tretiak, S.; Mukamel, S. J. Chem. Phys. 2000, 113, 36.

(24) Pople, J. A.; Segal, G. A. J. Chem. Phys. 1965, 43, S136.

(25) Pople, J. A.; Beveridge, D. L.; Dobosh, P. J. Chem. Phys. 1967, 47, 2026.

(26) Ridley, J. E.; Zerner, M. C. Theor. Chim. Acta 1973, 32, 111.

(27) Zerner, M. C.; Loew, G. H.; Kirchner, R. F.; Mueller-Westerhoff,

U. T. J. Am. Chem. Soc. 1980, 102, 589.

(28) McWeeny, R.; Sutchiffe, B. T. Methods of Molecular Quantum Mechanics; Academic Press: New York, 1976.

(29) Davidson, E. R. Reduced Density Matrixes in Quantum Chemistry; Academic Press: New York, 1976.

(30) Saad, Y. Numerical Methods for Large Eigenvalue Problems; University Press: Manchester, U.K., 1992.

(31) Davidson, E. R. J. Comput. Phys. 1975, 17, 87

(32) Mukamel, S.; Tretiak, S.; Wagersreiter, T.; Chernyak, V. Science 1997, 277, 781

(33) Tretiak, S.; Chernyak, V.; Mukamel, S. J. Phys. Chem. B 1998, 102,3310

(34) Gouterman, M. J. Mol. Spectrosc. 1961, 6, 138

(35) Edwards, L.; Dolphin, D. H.; Gouterman, M.; Adler, A. D. J. Mol. Spectrosc. 1971, 38, 16.

(36) Woller, E. K.; DiMagno, S. G. J. Org. Chem. 1997, 62, 1588.

(37) Hashimoto, T.; Choe, Y.-K.; Nakano, H.; Hirao, K. J. Phys. Chem

A 1999, 103, 1894.

(38) Edwards, W. D.; Zerner, M. C. Can. J. Chem. 1985, 63, 1763.

(39) Sekino, H.; Kobayashi, H. J. Chem. Phys. 1987, 86, 5045.

(40) Canters, G. W.; Jansen, G.; Noort, M.; van der Waals, J. H. J. Phys. Chem. 1976, 80, 2253.

(41) Pileni, M. P.; Gratzel, M. J. Phys. Chem. 1980, 84, 1822.

(42) Gouterman, M. In The porphyrins; Dolphin, D., Ed.; Academic Press: New York, 1978; Vol. III, pp 1.

(43) Keegan, J. D.; Stolzenberg, A. M.; Lu, Y.-C.; Linder, R. E.; Barth, G.; Moscowitz, A.; Bunnenberg, E.; Djerassi, C. J. Am. Chem. Soc. 1982 $104,4305$.

(44) Dorough, G. D.; Miller, J. R.; Huennekens, F. M. J. Am. Chem. Soc. 1951, 73, 4315 .

(45) Quimby, D. J.; Longo, F. R. J. Am. Chem. Soc. 1975, 97, 5111

(46) Ohya, T.; Takeda, J.; Sato, M. J. Phys. Chem. 2000, 104, 12045.

(47) Hu, X. C.; Damjanovic, A.; Ritz, T.; K., S. Proc. Natl. Acad. Sci. U.S.A. 1998, 95, 5935.

(48) Cory, M. G.; Zerner, M. C.; Xu, X. C.; Schulten, K. J. Phys. Chem $B$ 1998, 102, 7640 .

(49) Tretiak, S.; Middleton, C.; Chernyak, V.; Mukamel, S. J. Phys. Chem. B 2000, 104, 9540 .

(50) Tretiak, S.; Middleton, C.; Chernyak, V.; Mukamel, S. J. Phys. Chem. B 2000, 104, 4519.

(51) Tommasini, M.; Zerbi, G.; Chernyak, V.; Mukamel, S. J. Phys. Chem. A 2001, 105, 7057.

(52) Tretiak, S.; Saxena, A.; Martin, R. L.; Bishop, A. R. Phys. Rev. Lett. 2002, Submitted.

(53) Seely, G. R.; Calvin, M. J. Chem. Phys. 1955, 23, 1068.

(54) Su, W.; Cooper, T. M. Private communication. 